\title{
The George F. Jenks Map Collection
}

The Kenneth Spencer Research Library at the University of Kansas (KU) houses two collections related to the renowned cartographer George F. Jenks: the Personal Papers of George F. Jenks (call number PP 474) and the George F. Jenks Map Collection (MS 347). Dr. Jenks taught in the KU Geography Department from 1949-1986 and established the cartography program there. He became internationally recognized as a preeminent cartographer and scholar alongside peers Arthur Robinson, John Sherman, and Erwin Raisz. Both collections consist primarily of maps and documents that Jenks collected or produced in support of his research, teaching, and cartographic activities. Importantly, the map collection preserves the artwork underlying many of Jenks's published maps, including hand-drawn sketches, photo negatives, and compilation artwork. This article highlights items from both collections which, when viewed chronologically, document two parallel stories: one of an evolving research agenda, the other of an evolving discipline.

Jenks's career corresponded with the maturation of academic cartography and the emergence of computerized map production and statistical analysis. He spent many years developing and refining a formal cartographic curriculum, which he documented in the appropriately titled "An Improved Curriculum for Cartographic Training at the College and University Level" (Jenks 1953) and "The History and Development of Academic Cartography at Kansas: 1920-1980" (Jenks 1991). At the same time, Jenks devoted himself to a series of thematic mapping projects and research challenges. The map collection is arranged chronologically, and perusing its contents reveals five broad, overlapping phases of his map research and production: (1) Kansas-centric cartography, (2) data classification and generalization, (3) 3D representation, (4) map symbol perception, and (5) automated line generalization. The following sections highlight examples from each of these phases.

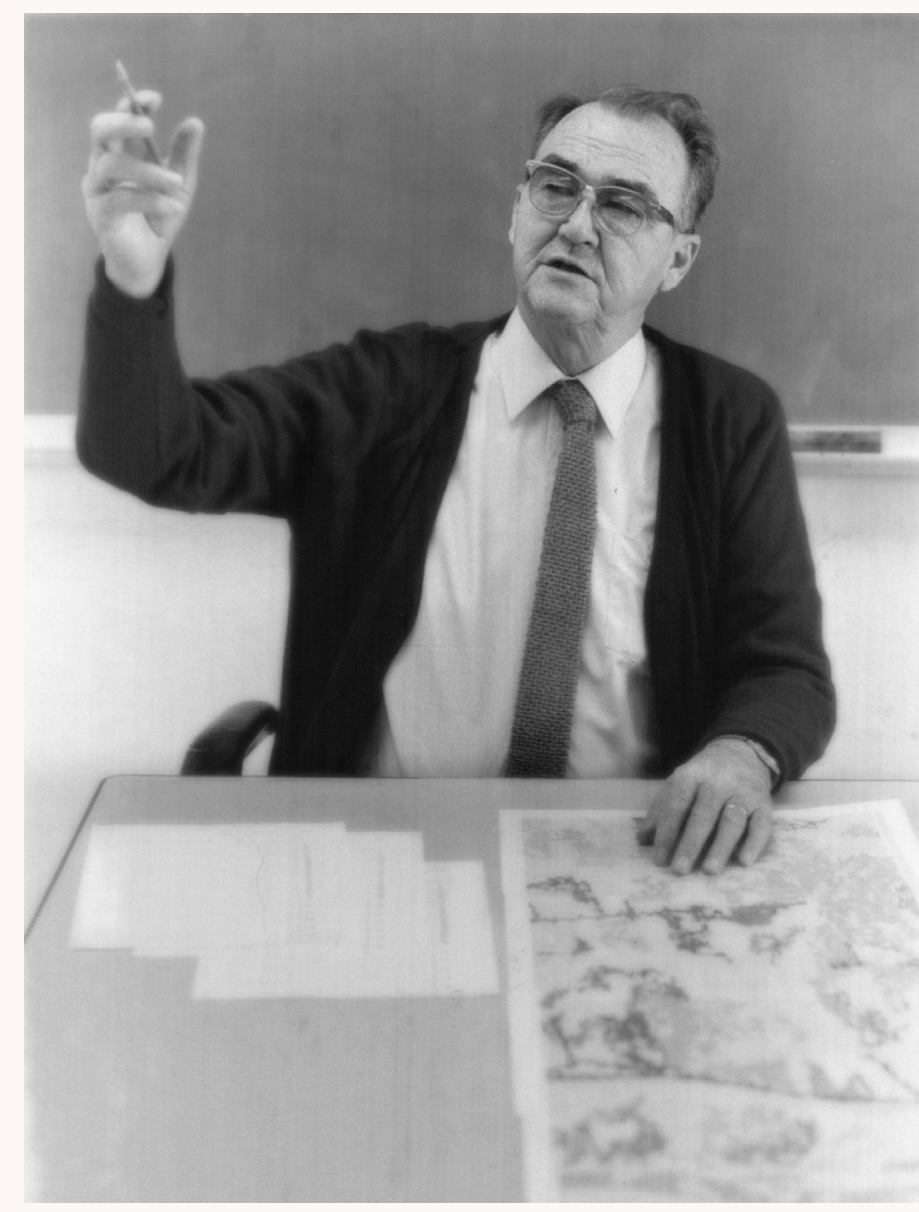

Figure 1. Dr. Jenks expounding on something map-related.

Jenks spent much of the 1950s producing statistical maps of Kansas. Representative examples of this work can be found in A Kansas Atlas (Jenks 1952) and the Kansas Industrial Resources atlas (Jenks 1956). At a time when most state mapping agencies were either nascent or nonexistent, having a cartographer of Jenks's caliber proved to be a boon for both the state and private industry. A Kansas Atlas was a rarity upon publication: a multicolor, in-depth statistical atlas devoted to a single state. Jenks mapped an exhaustive array of topics, ranging from population dynamics to agricultural productivity, using a variety of 

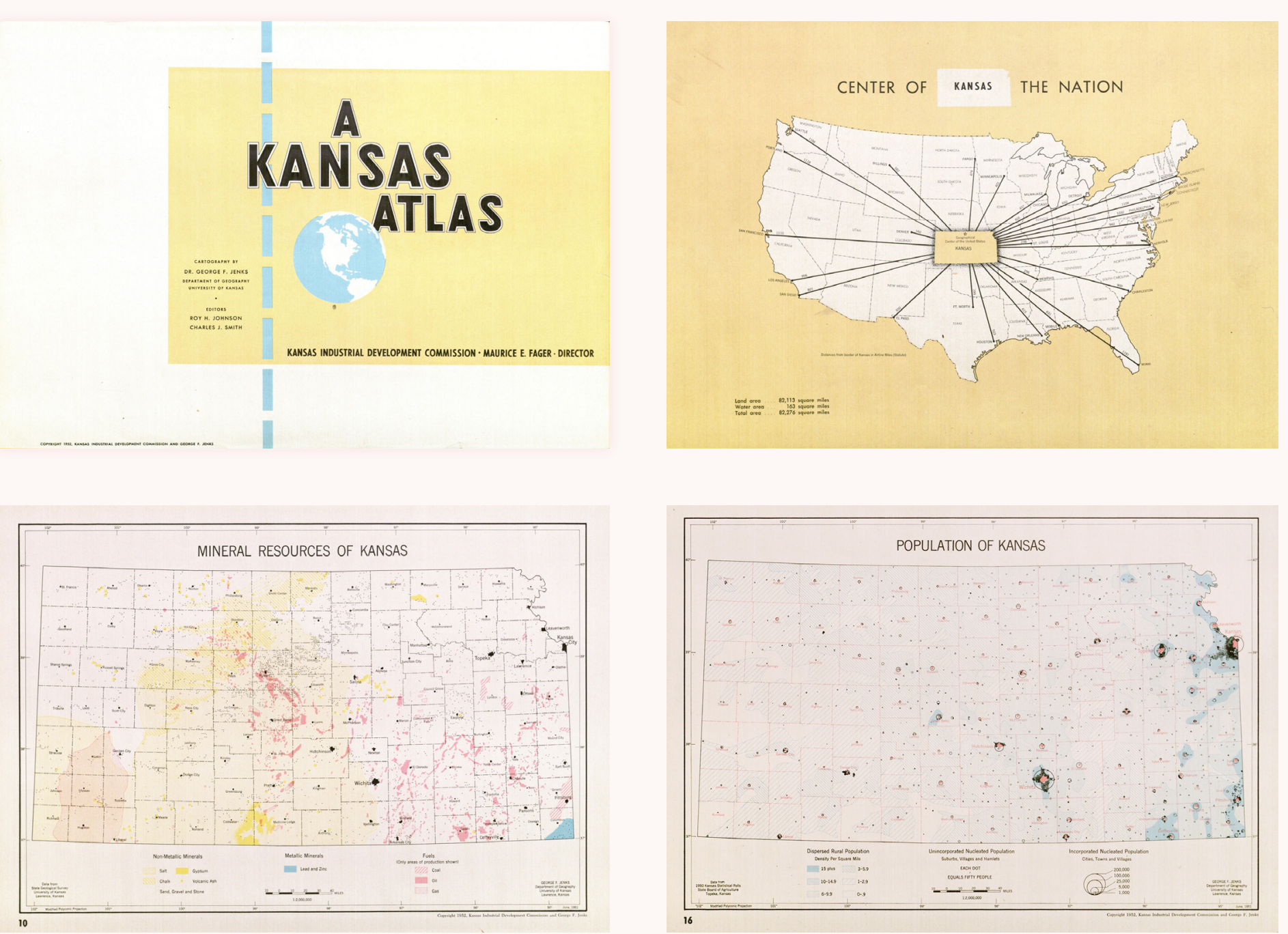

Figure 2. Selections from A Kansas Atlas (1952). The collection contains preliminary artwork, proof prints, and finalized prints of each graphic.

cutting-edge symbolization techniques. Robert McMaster (1997) claimed this was the first-ever state atlas. Jenks's thematic organization and map symbolization methods were pioneering efforts of the time; those methods continue to be used today.

The Kansas Industrial Resources atlas (1956) is a masterclass in two- and three-color map design and artful cartographic generalization. To this day mapmakers struggle with the challenge of generalizing data so that important information stands out while preserving the accuracy of that information. Jenks simplified and elevated mundane topics such as railroad freight service and electricity grids into visually arresting, statistically accurate map displays. Figure 3 presents several examples of this aesthetic. For instance, the Annual Stream Flow map uses line width alone to communicate how Kansas streams carry more water as they move south and east.

Beginning in the early 1960s, data classification and generalization became a prominent theme of Jenks's research. Two of his publications, "Generalization in Statistical Mapping” (Jenks 1963) and "Class Intervals for Statistical Maps" (Jenks and Coulson 1963), remain seminal pieces in the cartographic literature. Through this research, Jenks helped to systematize the process for classifying spatial data and devised rules to guide the selection of effective classification methods for choropleth maps. The research culminated in his most recognizable contribution to cartography, the eponymous Jenks Optimization and Jenks Natural Breaks methods of data classification (Jenks and Caspall 1977). The map collection contains the maps and 

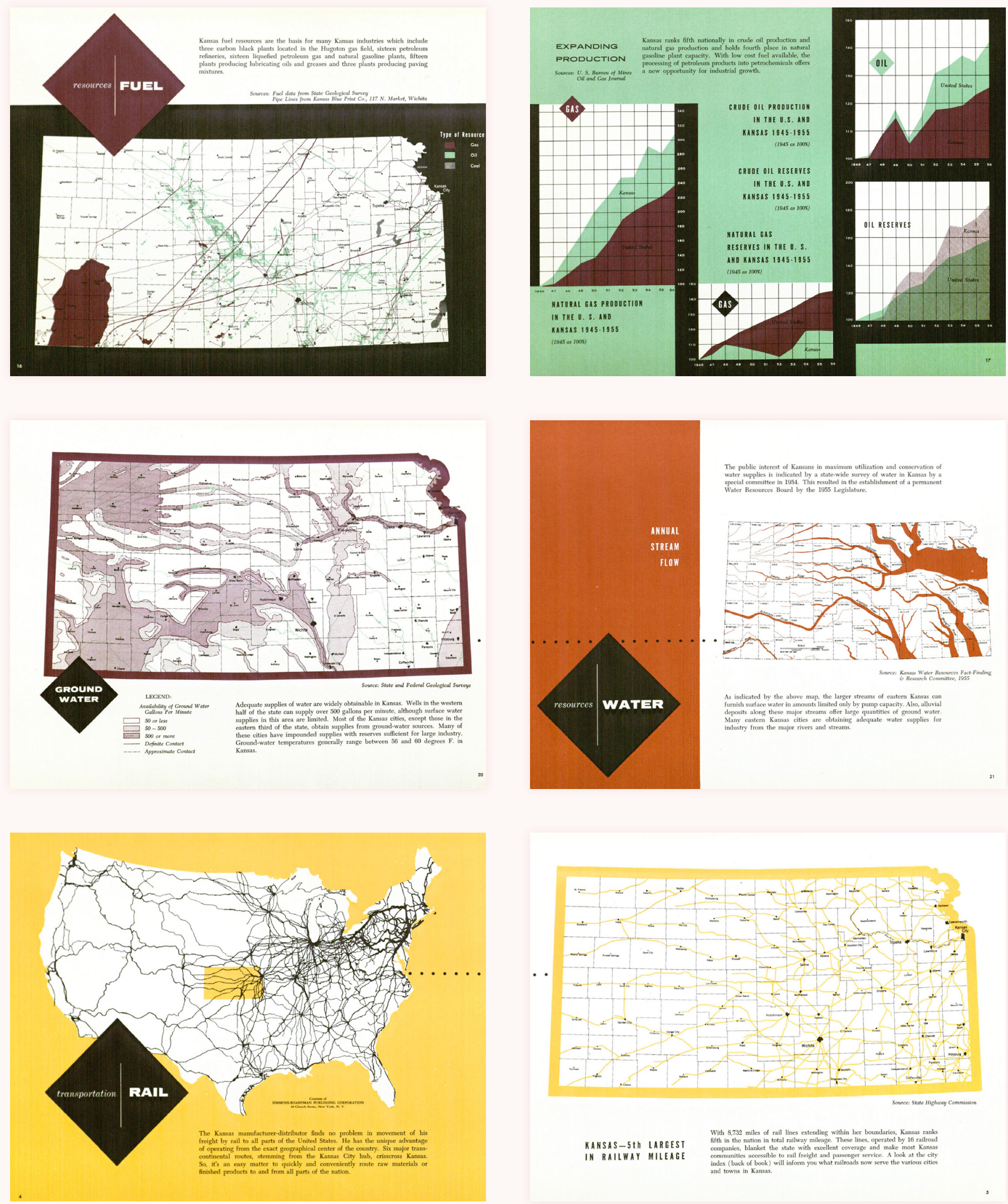

Figure 3. Selections from the Kansas Industrial Resources atlas (1956). The collection contains preliminary artwork, proof prints, and finalized prints of each graphic. 

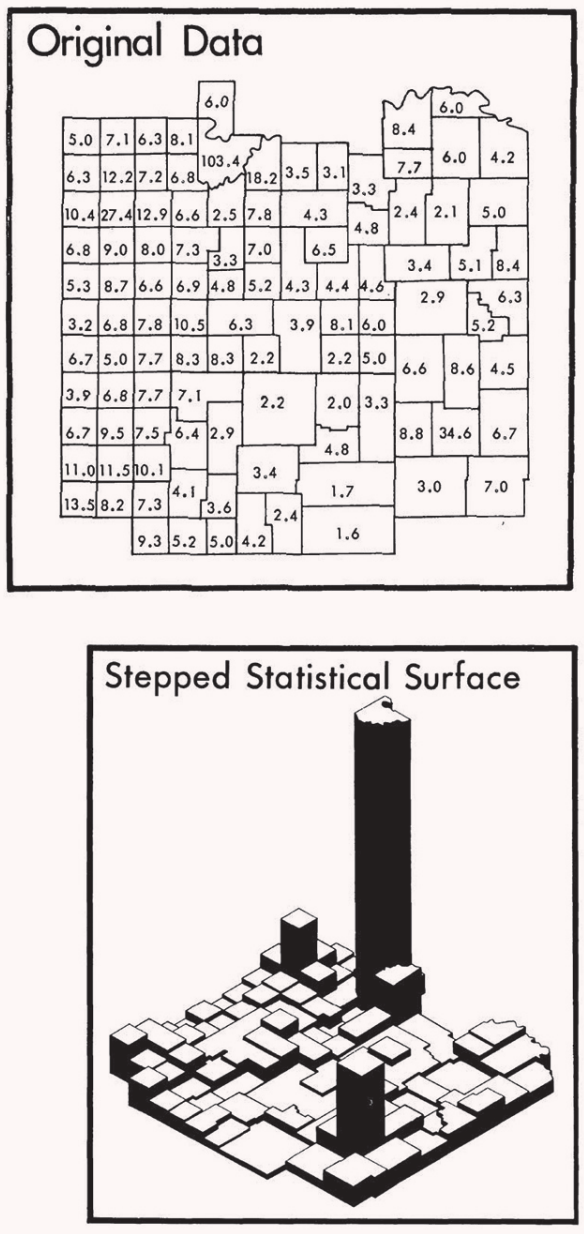

Smoothed Statistical Surface

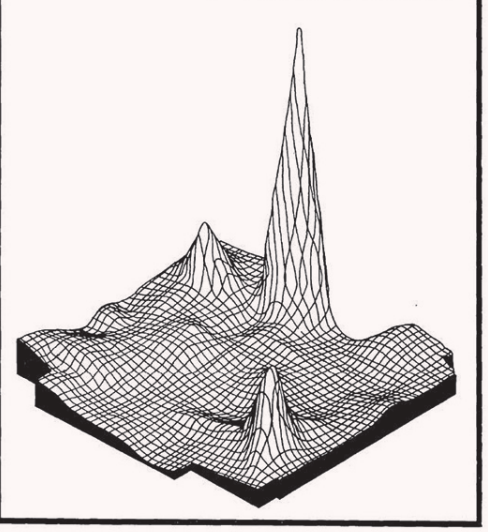

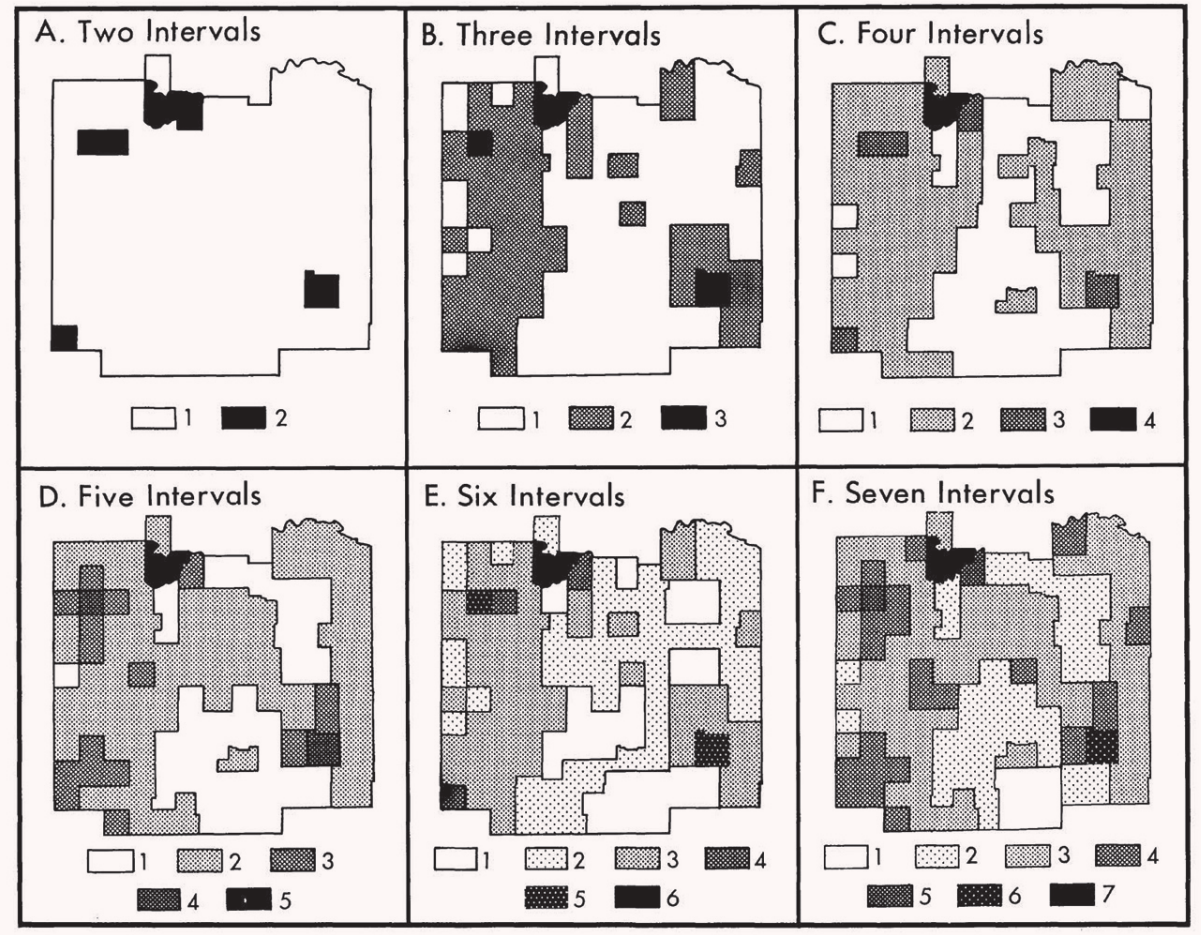

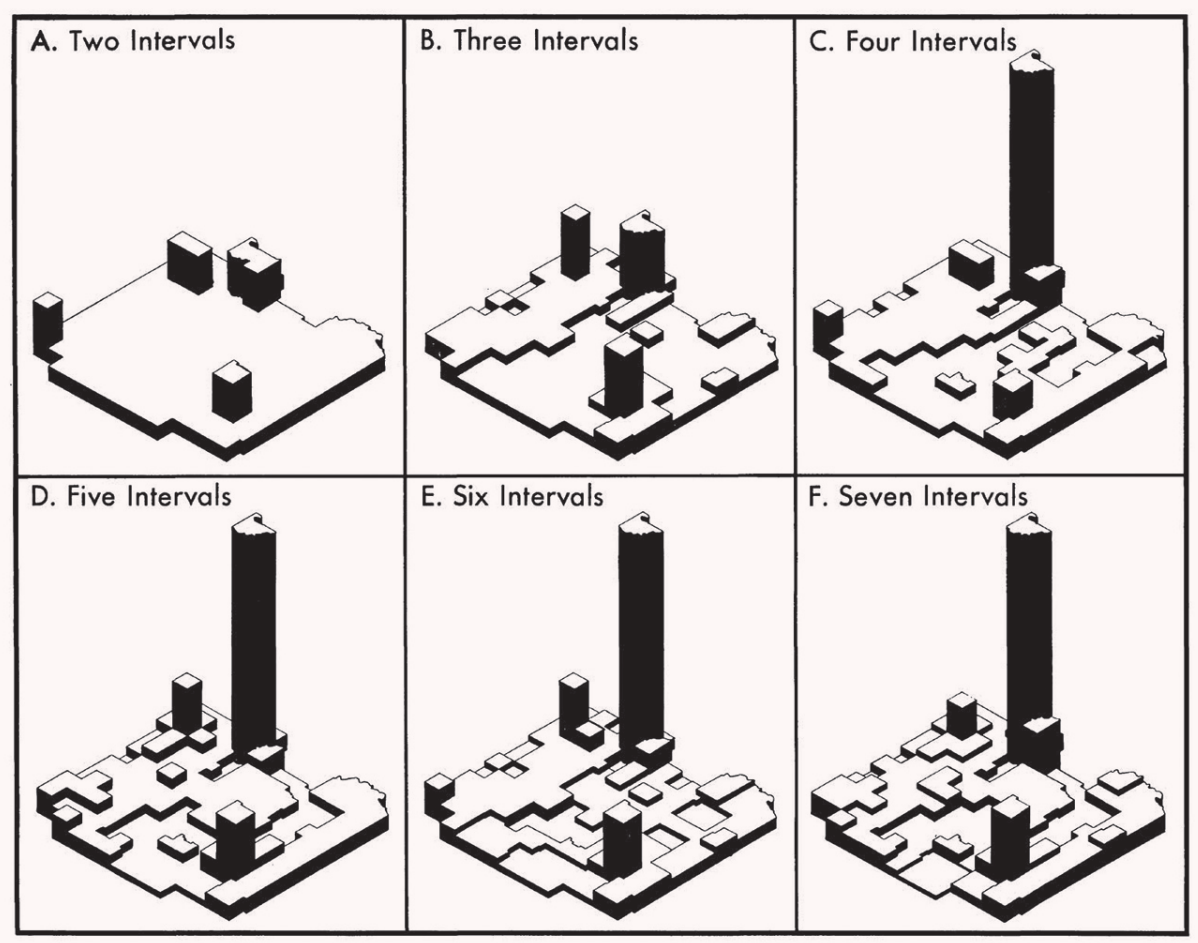

Figure 4. Graphics from "Class Intervals for Statistical Maps" (Jenks and Coulson 1963), illustrating the process of data generalization. Different class intervals affect the appearance of the data on the map. The collection contains the preliminary artwork, photographic negatives and masks, test prints, and finalized prints of each graphic. 

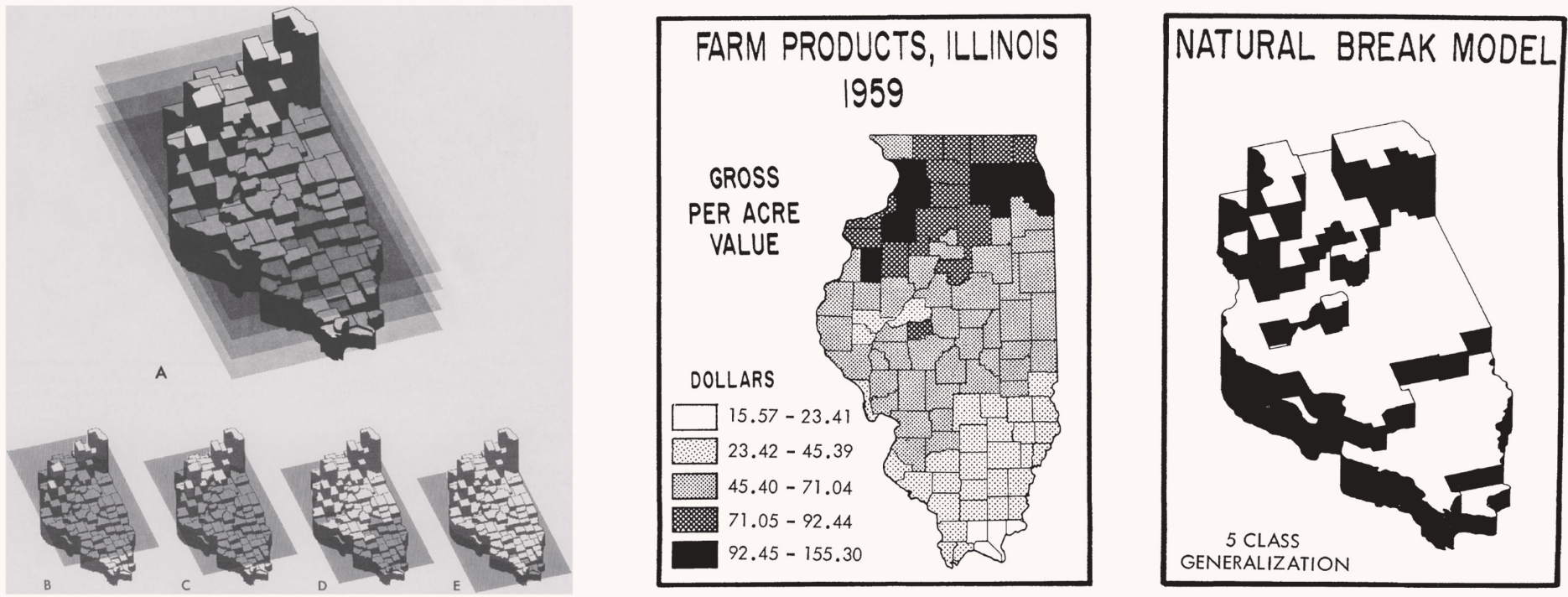

Figure 5. Graphics from "Error on Choroplethic Maps: Definition, Measurement, Reduction" (Jenks and Caspall 1971), which introduced the Natural Breaks method of data classification. The collection contains the preliminary artwork, photographic negatives and masks, photographic positives, test prints, compilation artwork, and finalized prints of each graphic.

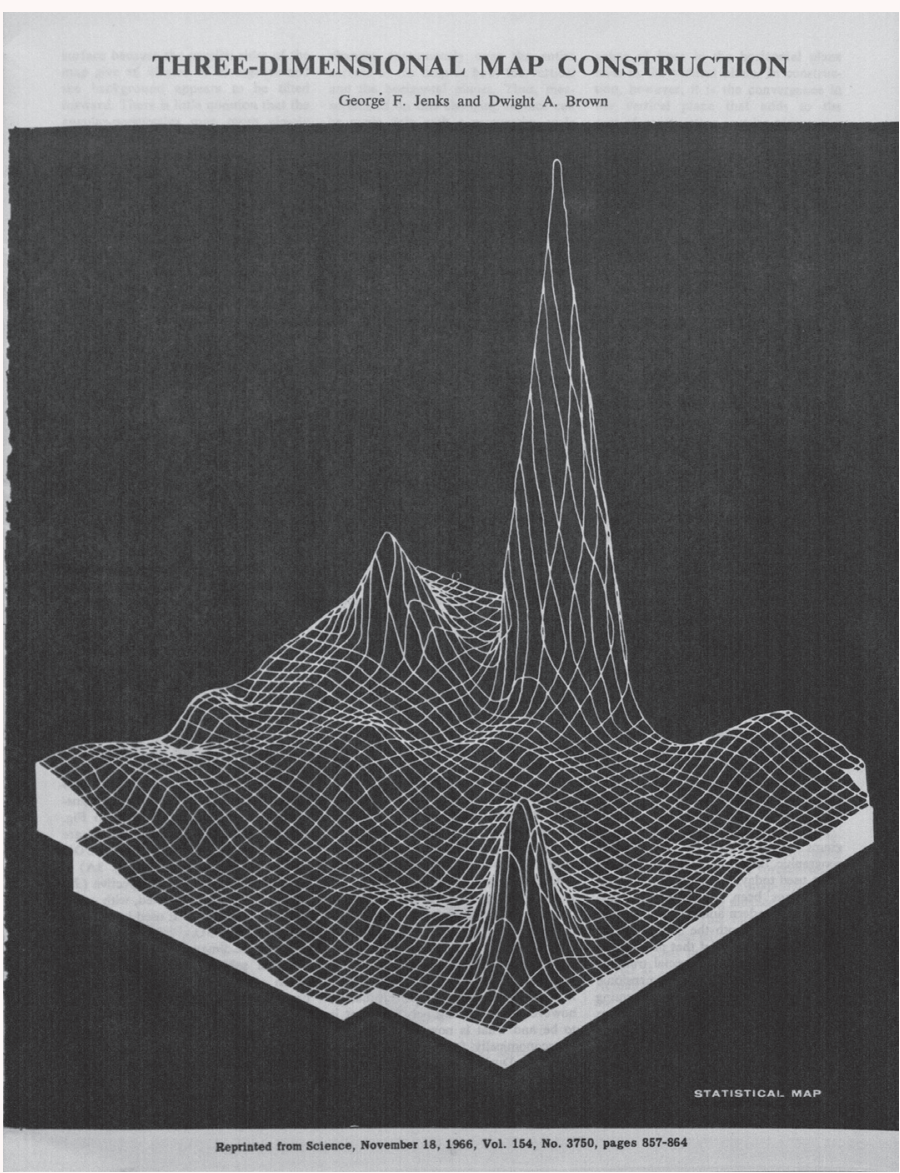

Figure 6. A three-dimensional "smoothed statistical surface" map representing population density in central Kansas. This graphic graced the cover of the November 18, 1966 issue of Science. Jenks originally created this graphic for his class intervals research. The collection contains the preliminary artwork, photographic negatives and masks, photographic positives, test prints, compilation artwork, and finalized prints of each graphic. graphics Jenks created to devise and illustrate these two concepts, some of which are still used in contemporary cartography textbooks.

Another staple of Jenks's research was three-dimensional map construction. From the mid-1960s onward he refined 3D mapping techniques, first by hand and later using computers. Jenks ran many experiments and published several papers exploring map construction and optimal viewing perspectives in three dimensions. One publication, “Three Dimensional Map Construction” (Jenks and Brown 1966), remains highly recognizable within cartographic circles, and also featured one of Jenks's most famous maps: a three-dimensional representation of population density in central Kansas. Interestingly, this graphic was initially produced for his 1963 paper on class intervals (Jenks and Coulson 1963) but he continued to use it as the basis for many successive graphics and ideas. Given the time-intensive nature of pre-computer, photo-mechanical map production, it is not surprising that many of his maps appear again and again throughout the collection.

Jenks believed that understanding map users was crucial for effective map design, and many of his experiments were designed as user studies to explore their perception and understanding of mapped information. His concern for the user's experience led him to psychophysics and the psychology of perception. Beginning in the early 1970s, Jenks incorporated eye movement into his user studies. The examples provided in Figure 7 were used in experiments 


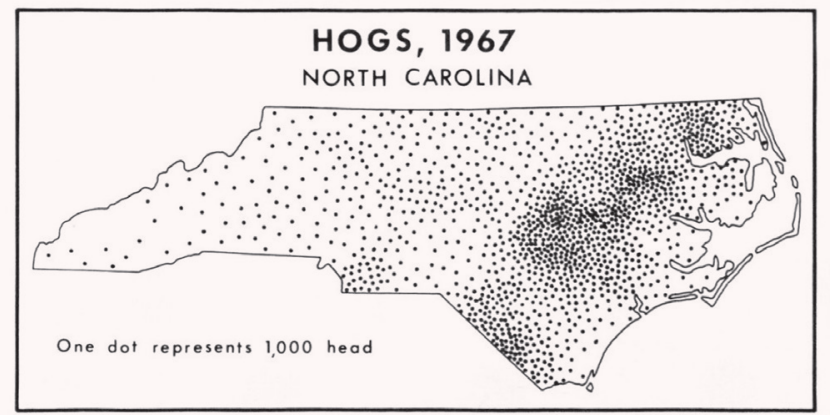

Fig. 1 - This small scale dot map is a commonly used type of thematic map. Some readers of such maps seen to group clusters of dots into regions of homogeneity while others try to extract factual data as they would
from a census table.

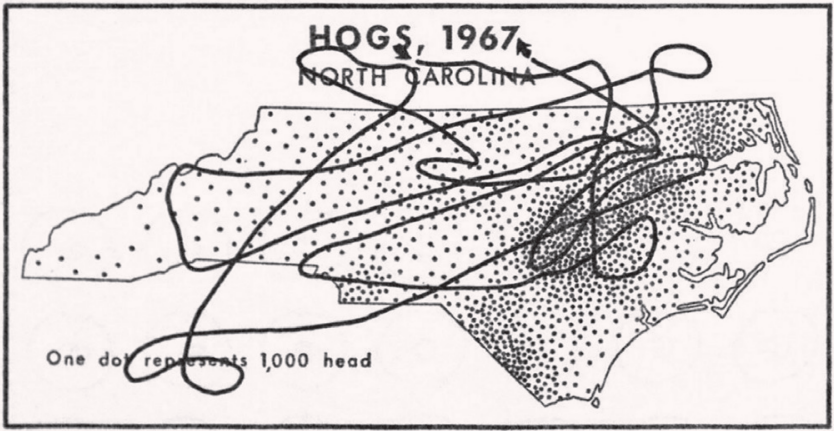

Fig. 6 - The scan path of a graduate student reading the map. If one follows this path it soon becomes wident that redundancy and erratic movements of the ere are part of the map reading process. This is also true of the scan paths of readers looking at pictures and other types of illustrations.

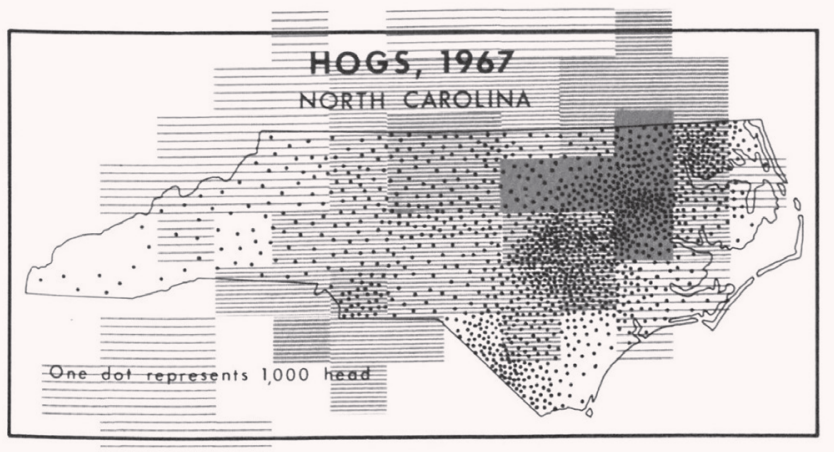

FIXATION TIME IN SECONDS

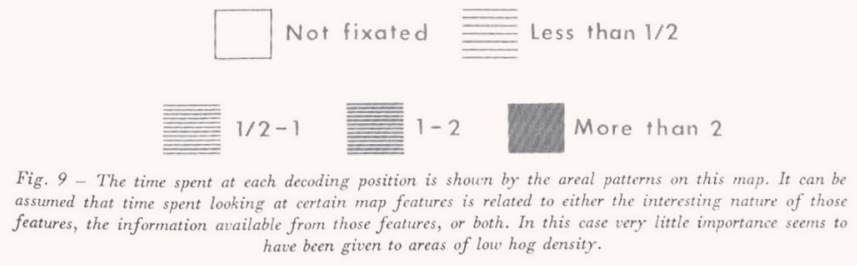

Figure 7. Jenks frequently featured North Carolina hog maps in his cartographic experiments. These graphics appear in his 1973 paper "Visual Integration in Thematic Mapping: Fact or Fiction?" The collection contains literally hundreds of photographic negatives, photographic positives, test prints, finalized prints, and experiment booklets of these and similar dot density hog maps. reported in "Visual Integration in Thematic Mapping: Fact or Fiction?" (Jenks 1973) and "The Average Map Reader Lives!” (Jenks 1974). This early foray into perception served as a template for other cartographers to build upon, to the point where cognitive psychology became and remains an essential component of cartographic research.

From the late 1970s until his retirement, Jenks's gaze shifted to the burgeoning realm of computerized cartography. Having run the KU cartographic production laboratory for decades, Jenks was keenly aware that new technologies would reshape conventional map production workflows. What caught his particular interest was how the shift from manual to digital techniques would affect the representation of linear features such as coastlines and rivers at various scales. Consequently, Jenks spent the last major "phase" of his career refining methods of automated line generalization. Both collections contain an abundance of plotted lines and maps Jenks created using his own generalization algorithms and indicates that he remained a prolific researcher even near the end of his career. These items also highlight how Jenks embraced new technologies to accommodate-and possibly even answer-old cartographic questions, as well as continually improve the overall quality of finished maps. Automated feature generalization remains a persistent challenge as interactive map standards continue to evolve.

This article only skims the surface of Jenks's celebrated career and the contents of Jenks's personal papers and map collection. The reader should note that while many of the maps featured here may not appear noteworthy by today's standards or software capabilities, they were considered revolutionary and cutting edge in their time. Perusing both his personal papers and map collection reveals the breadth and depth of Jenks's cartographic expertise. He was an innovator, recognized as an expert in symbology, cartographic reproduction techniques, and the links between cartography, psychology, and human factors. The Jenks collections document the breadth and depth of all of these scholarly and investigatory activities. A key strength: the exhaustive preservation of material allows one to follow an entire creative process from its earliest stages to the final, published product.

The Kenneth Spencer Research Library is open to the general public, and the contents of both the map collection and Jenks's personal papers are available to view by appointment in the library's reading room. I am indebted to Dr. 
Karen Cook, Special Collections Librarian in the Kenneth Spencer Research Library, for her guidance during the archiving and processing of the Jenks Map Collection.

\section{REFERENCES AND FURTHER READING}

Jenks, George F. 1952. A Kansas Atlas. Topeka, KS:

Kansas Industrial Development Commission.

_ 1953. "An Improved Curriculum for

Cartographic Training at the College and University

Level." Annals of the Association of American Geographers

43 (4): 317-331. doi: 10.2307/2560899.

- 1956. Kansas Industrial Resources. Topeka, KS:

Kansas Industrial Development Commission.

1963. "Generalization in Statistical Mapping."

Annals of the Association of American Geographers 53 (1):

15-26. doi: 10.1111/j.1467-8306.1963.tb00429.x.

1973. "Visual Integration in Thematic

Mapping: Fact or Fiction?” In International Yearbook of Cartography XIII, edited by E. Arnberger and F.

Aurada, 27-35. Gütersloh, Germany: Kartographisches Institut Bertelsmann.

1979. "Thoughts on Line Generalization."

In Proceedings of the International Symposium on

Cartography and Computing: Applications in Health

and Environment, edited by Robert T. Aangeenbrug,

209-220. Falls Church, VA: American Congress on

Surveying and Mapping.

. 1981. "Lines, Computers, and Human Frailties."

Annals of the Association of American Geographers 71 (1):

1-10. doi: 10.1111/j.1467-8306.1981.tb01336.x.

1989. "Geographic Logic in Line Generalization, Numerical Generalization in Cartography."

Cartographica 26 (1): 27-42. doi: 10.3138/

1426-1756-7052-536k.

1991. "The History and Development of

Academic Cartography at Kansas: 1920-1980."

Cartography and Geographic Information Systems 18 (3):

161-66. doi: 10.1559/152304091783786853.
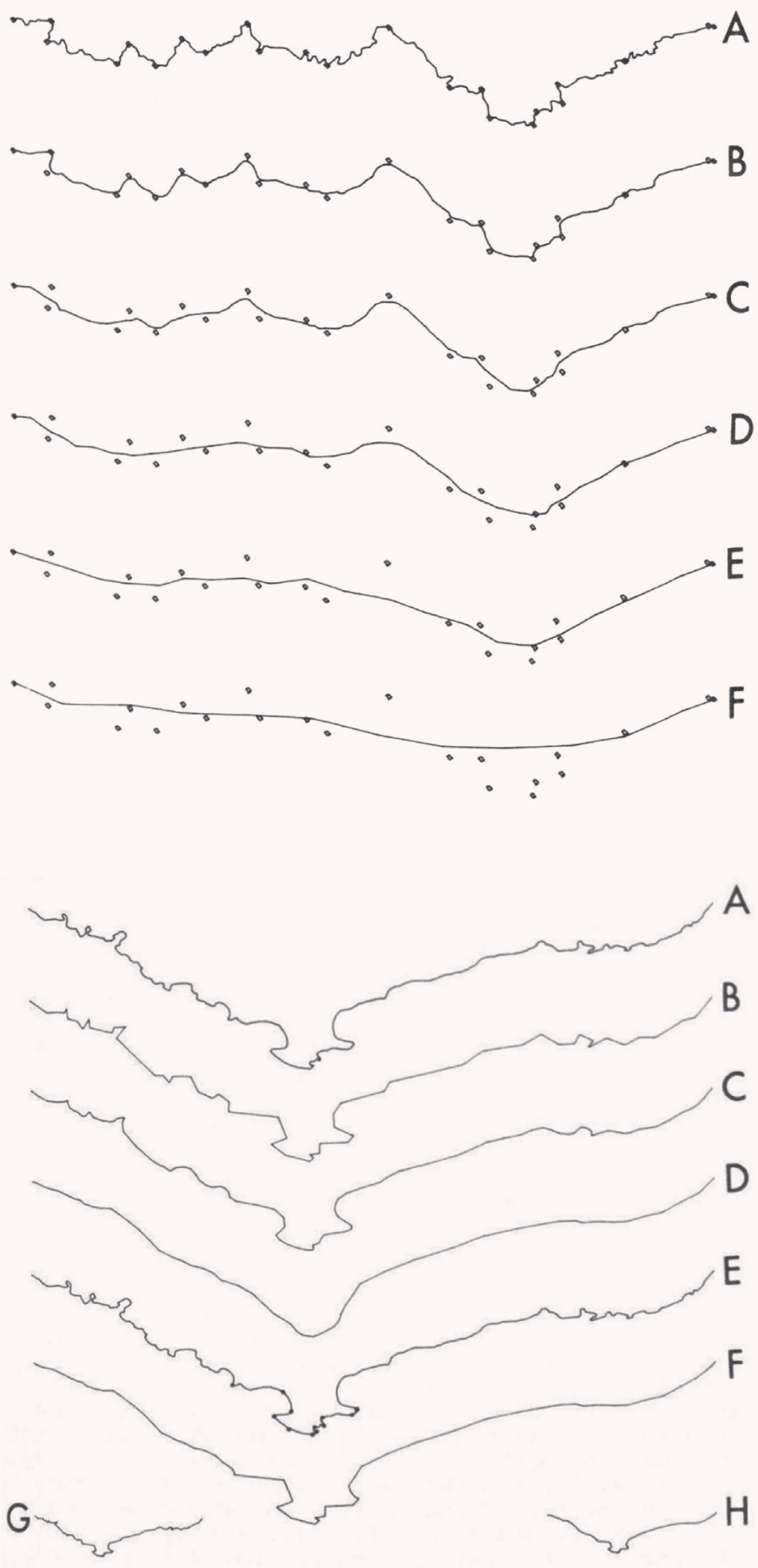

Figure 8. Jenks spent over a decade developing and refining simplification algorithms for multiscale line generalization. These graphics, from "Thoughts on Line Generalization" (1979), illustrate how Jenks used selective coordinate pairs to digitally smooth and retain the significant details of linear features. The map collection contains hundreds of computer printouts similar to these examples, many annotated with notes, formulas, and handdrawn comparisons. 
Jenks, George F., and Dwight A. Brown. 1966. "Threedimensional Map Construction.” Science 154 (3751): 857-864. doi: 10.1126/science.154.3751.857.

Jenks, George F., and Fred C. Caspall. 1971. "Error on Choroplethic Maps: Definition, Measurement, Reduction." Annals of the Association of American Geographers 61 (2): 217-244. doi: 10.1111/j.14678306.1971.tb00779.x.

Jenks, George F., and Michael R. C. Coulson. 1963. "Class Intervals for Statistical Maps." In International Yearbook of Cartography III, edited by Eduard Imhof, 119-134. Zürich: Orell Füssli Verlag.

Jenks, George F., and Duane Sidney Knos. 1961. "The Use of Shading Patterns in Graded Series." Annals of the Association of American Geographers 51 (3): 316-334. doi: 10.1111/j.1467-8306.1961.tb00381.x.
McMaster, Robert. 1997. "In Memoriam:

George F. Jenks (1916-1996).” Cartography and Geographic Information Science 24 (1): 56-59. doi: 10.1559/152304097782438764.

McMaster, Robert and Susanna McMaster. 2002. "A History of Twentieth-Century American Academic Cartography." Cartography and Geographic Information Science 29 (3): 312-315. doi: $10.1559 / 152304002782008486$.

Mersey, Janet E. 2015. “Choropleth Map." In The History of Cartography, Volume 6: Cartography in the Twentieth Century, edited by Mark Monmonier, 220-225. Chicago: University of Chicago Press. 